\section{Medikamentell abort hos avtalespesialist}

ORIGINALARTIKKEL

\section{AASE SERINE DEVOLD PAY}

E-post: aase.serine.devold.pay@helsedir.no Avdeling sykehustjenester

Helsedirektoratet

Hun har bidratt med analyse, tolkning av data, vært hovedansvarlig for utarbeiding av manuset og godkjent den endelige versjonen.

Aase Serine Devold Pay (f. 1966) er jordmor, ph.d. og seniorrådgiver.

Forfatter har fylt ut ICMJE-skjemaet og oppgir ingen interessekonflikter.

\section{RUNA SIGRID AAB $\varnothing$}

Sandvika spesialistsenter

Hun har bidratt med idé, utforming, utarbeiding av manuset og godkjent den endelige versjonen. Runa Sigrid Aabø (f. 196o) er lege, spesialist i fødselshjelp og kvinnesykdommer og avtalespesialist. Forfatter har fylt ut ICMJE-skjemaet og oppgir ingen interessekonflikter.

\section{INGER $\varnothing K L A N D$}

Avdeling sykehustjenester

Helsedirektoratet

og

Kvinne- og barneklinikken

Stavanger universitetssjukehus

Hun har bidratt med tolkning av data, utarbeiding av manuset og godkjent den endelige versjonen. Inger Økland (f. 1958) er dr.philos., spesialist i fødselshjelp og kvinnesykdommer, seniorrådgiver og forskningssjef.

Forfatter har fylt ut ICMJE-skjemaet og oppgir ingen interessekonflikter.

\section{TORUNN JANBU}

Avdeling sykehustjenester

Helsedirektoratet

Hun har bidratt med idé, utforming, utarbeiding av manuset og godkjent den endelige versjonen. Torunn Janbu (f. 1954) er overlege dr.med., spesialist i generell kirurgi og i ortopedisk kirurgi og avdelingsdirektør.

Forfatter har fylt ut ICMJE-skjemaet og oppgir ingen interessekonflikter.

\section{OLE-ERIK IVERSEN}

Klinisk institutt

Universitetet i Bergen

og

Kvinneklinikken

Haukeland universitetssykehus

Han har bidratt med idé, utforming, utarbeiding av manuset og godkjent den endelige versjonen. Ole-Erik Iversen (f. 1945) er professor emeritus og tidligere overlege. Han har arbeidet med 
implementeringen av medikamentelt svangerskapsavbrudd i Norge fra 1998.

Forfatter har fylt ut ICMJE-skjemaet og oppgir ingen interessekonflikter.

\section{METTE LøKELAND}

Prosjektgruppe for abort hos avtalespesialister

Helsedirektoratet

Hun har bidratt med idé, utforming, tolkning av data, utarbeiding av manuset og godkjent den endelige versjonen.

Mette Løkeland (f. 1971) er spesialist i fødselshjelp og kvinnesykdommer, ph.d. (avhandlingens tittel var Implementation of medical abortion in Norway 1998-2013) og overlege.

Forfatter har fylt ut ICMJE-skjemaet og oppgir ingen interessekonflikter.

\section{BAKGRUNN}

I Norge utføres abort kun i offentlige sykehus. I 2010 besluttet Helse- og omsorgsdepartementet å iverksette et toårig prøveprosjekt som ga avtalespesialister i fødselshjelp og kvinnesykdommer adgang til å tilby medikamentell abort før utgangen av 9. svangerskapsuke. Prøveprosjektet ble igangsatt 1.3.2015 og varte til 31.3.2017. I denne artikkelen presenterer vi de første erfaringene, herunder hvordan behandlingstilbudet ble mottatt av kvinnene.

\section{MATERIALE OG METODE}

Gravide med en svangerskapsvarighet $<63$ dager ultrasonografisk vurdert, som oppsøkte avtalespesialist for medikamentell abort, ble fortløpende inkludert i prosjektet $(n=476)$. Kvinnene inntok 200 mg mifepriston peroralt på legekontoret, 36-48 timer senere satte de selv $800 \mu$ g misoprostol vaginalt hjemme. Informasjon ble innhentet ved spørreskjema på den første konsultasjonen, under aborten og ved etterkontrollen 2-4 uker etter aborten.

\section{RESULTATER}

Under aborten rapporterte 66 \% (296/450) moderat eller sterk smerte og $79 \%$ (358/451) moderat eller sterk blødning. De fleste opplevde det som trygt å være hjemme. $96 \%$ (390/406) ville valgt medikamentell abort hos avtalespesialist ved en eventuell senere abort, og 97 \% (392/405) ville anbefalt behandlingstilbudet til andre i samme situasjon.

\section{FORTOLKNING}

Kvinnene i studien opplevde abortbehandling hos avtalespesialist som trygt. Tilbudet gir større valgfrihet til gravide som ønsker abort, og pasientene er tilfredse.

Provosert abort er en av de vanligste behandlingene innenfor reproduktiv helse. På verdensbasis er abortantallet synkende, mens antallet utrygge aborter er økende (1). I Norge har abortantallet per år vært relativt stabilt, med 13977 provoserte aborter i 1998 og $13169 \mathrm{i}$ 2016, samtidig som det fra 2006 har vært en betydelig nedgang i provoserte aborter blant yngre kvinner (2). Frem til 1998 ble alle aborter i Norge utført som et kirurgisk inngrep, men i 1998 ble tilbudet om medikamentell abort innført (3). Fra 1998 har det vært en tilnærmet total omlegging av abortbehandlingen til medikamentell behandling. I 2006 var andelen abortinngrep som ble gjennomført medikamentelt 45\%, og i 2016 var andelen 88 \% (2). De fleste abortene utføres tidlig i svangerskapet. I 2016 ble 81 \% av alle abortene utført før 9. svangerskapsuke, og av disse ble $92 \%$ utført medikamentelt.

Abortbehandling er regulert i abortloven (4), hvor det fremkommer at behandlingen skal utgå fra offentlige sykehus, hvor en lege har det medisinskfaglige ansvaret både for aborten, medisinutleveringen og etterkontrollen. I Norge utføres medikamentell abort med en kombinasjon av antiprogesteronet mifepriston og prostaglandinet misoprostol (5). Det anbefales at kvinner med svangerskapsvarighet under 9 uker (63 dager) inntar mifepriston 
på sykehuset (poliklinisk), og innlegges 24-48 timer senere som dagpasient, der hun inntar misoprostol eller at hun fullfører behandlingen hjemme. Ved graviditet mellom 9. og 12. svangerskapsuke fullfører kvinnen behandlingen på sykehus.

Flere land praktiserer abortbehandling utenfor offentlige sykehus. I Danmark kom det i 2005 en lovendring som åpnet for at abort kan foretas utenfor sykehus i spesiallegepraksis (6). Også i Sverige og Nederland tilbys medikamentell abortbehandling utenfor offentlig sykehus. Verdens helseorganisasjon anbefaler at abortbehandling bør være lett tilgjengelig, noe som innebærer at tilbudet bør være tilgjengelig på primærhelsetjenestenivå og med etablerte henvisningsrutiner til spesialisthelsetjenesten (7). Dette samsvarer med nasjonale prinsipper (laveste effektive omsorgsnivå, LEON) og er nedfelt i en rekke offentlige utredninger og planer.

Etter initiativ fra Norsk gynekologisk forening varslet Helse- og omsorgsdepartementet i statsbudsjettet for 2011 (8) at «det skal startes et to års prøveprosjekt som gir privatpraktiserende gynekologer med avtale med regionale helseforetak (avtalespesialister) adgang til å tilby medikamentelt utført svangerskapsavbrudd (abortpille) som hjemmebehandling før utgangen av 9. svangerskapsuke». Helsedirektoratet fikk i 2010 oppdraget med å planlegge, igangsette og evaluere prosjektet i nært samarbeid med fagmiljøet.

Det har vært dialog mellom Helse- og omsorgsdepartementet og Helsedirektoratet om de faglige vurderingene som ligger til grunn for praktiseringen av medikamentell abort, og nødvendig avklaring og tilrettelegging i forhold til lover, forskrifter, medikamentutlevering og rapportering (fig 1). I mars 2015 ble prosjektet etablert i Oslo, Sandvika, Stavanger og Bergen, hos til sammen ni avtalespesialister, med en varighet på to år. Hovedformålet med prøveprosjektet var å finne frem til arbeidsmåter som kan gi gravide som ønsker abort, større valgmuligheter, i tillegg til å prøve ut de faglige og organisatoriske sidene ved å tilby medikamentelt utført abort hos avtalespesialister.

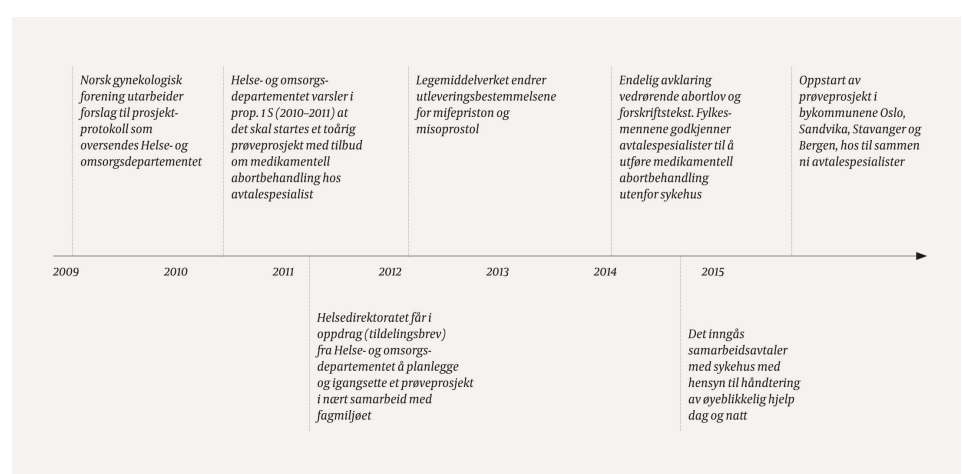

Figur 1 Tidslinje for implementering av prøveprosjektet

I denne artikkelen beskriver vi hvordan behandlingstilbudet ble mottatt hos en serie av 476 kvinner med en svangerskapsvarighet $<63$ dager, som selv valgte medikamentell abort hos avtalespesialist.

\section{Materiale og metode}

$\mathrm{Ni}$ avtalespesialister med spesiell interesse for pasientgruppen ble gitt adgang til å tilby medikamentell abort i avtalepraksis i prosjektperioden. I vurderingen av hvilke avtalespesialister som kunne være aktuelle for å delta i prøveprosjektet, ble det vektlagt at avtalespesialisten selv ønsket å delta. Det ble også stilt visse faglige krav til

avtalespesialistene. Informasjon om prosjektet ble sendt ut til alle helseforetak, fastleger og helsestasjoner i Oslo, Akershus, Hordaland og Rogaland. Det har også vært informasjon om prosjektet på nettsiden helsenorge.no/gravid og på Helsedirektoratets egne nettsider om graviditet.

Alle gravide med en dokumentert svangerskapsvarighet på 62 dager eller mindre, som fikk utført medikamentell abort hos avtalespesialist, ble fortløpende inkludert i studien. 
Fastsettelse av svangerskapets varighet ble basert på ultralydundersøkelse med hode-setemål. Det ble gitt skriftlig og muntlig informasjon om inngrepets art og medisinske virkninger, i tillegg til tilbud om informasjon og veiledning om samfunnets støtteordninger (jf. abortloven § 2). Alle valgte selv denne behandlingen hos avtalespesialist, etter informert samtykke.

To konsultasjoner ble planlagt for hver kvinne (fig 2). Ved første konsultasjon inntok kvinnene $200 \mathrm{mg}$ mifepriston per os under overvåkning. Kvinnene fikk beskjed om å sette $800 \mathrm{\mu g}$ misoprostol vaginalt og samtidig innta $1000 \mathrm{mg}$ paracetamol, $100 \mathrm{mg}$ diklofenak og $10 \mathrm{mg}$ metoklopramid per os to dager senere. Det ble gitt informasjon om forventet blødningsmengde og at kvinnen ved blødning utover normalt skulle ta kontakt med avtalespesialist eller nærmeste sykehus, definert som blødning utover seks store bind (nattbind) i løpet av to timer. Kvinnene ble oppringt av helsepersonell fra legekontoret etter at misoprostol var satt, for å følge opp smerter, blødning og trygghet. Alle deltagerne i prosjektet fikk tilbud om etterkontroll med prevensjonsveiledning, to til fire uker etter abortbehandlingen.

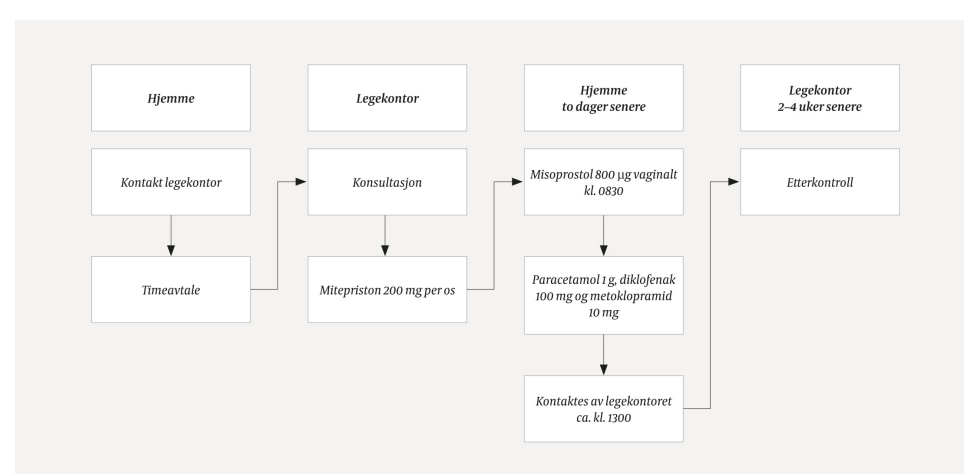

Figur 2 Flytskjema for medikamentelt utført abort hos avtalespesialist

Informasjon om blødningsmengde, smerter, trygghet og tilfredshet ble innhentet ved bruk av spørreskjema under aborten og på etterkontrollen. På telefon under aborten ble kvinnene bedt om å vurdere blødningen som ingen, lett, moderat, mye eller svært mye, og smerter som ingen, lette, moderate eller sterke. Det ble spurt om opplevd trygghet under abortbehandlingen ved spørsmål som: Kjennes det trygt å være hjemme under behandlingen? Grad av trygghet ble angitt på en tipunkts Likert-skala, hvor 1 var minst trygg og 10 var mest trygg. Ved etterkontrollen ble kvinnene igjen spurt om opplevd trygghet under abortbehandlingen. I tillegg ble det spurt om personlig tilfredshet, herunder om hun ved et eventuelt senere svangerskapsavbrudd ville valgt abort hos avtalespesialist og anbefalt tilbudet til andre i samme situasjon, med ja/nei-svaralternativer. Avtalespesialistene ble også bedt om å oppgi tidsbruk ved første konsultasjon og etterkontrollen, og om kvinnen hadde behov for ekstra konsultasjoner mellom de planlagte konsultasjonene og/eller kontakt med annet helsepersonell (fastlege, sykehus).

Deskriptive analyser er presentert med median og variasjonsbredde for kontinuerlige data og med frekvens og prosentandel for kategoriske data. Fordeling av skår på trygghet er visualisert med histogram. Bare anonyme data ble registrert og analysert. Det var ikke koblingsn $\varnothing$ kkel eller registrering av personnummer eller navn. Prosjektet ble behandlet av regional etisk komité sør-øst 17.9.2014 (ref.nr.: 2014/1427) og ble vurdert til ikke å være fremleggingspliktig.

\section{Resultater}

476 kvinner ble fortløpende inkludert i prosjektet i studieperioden. Median alder var 30 år (variasjonsbredde 17-47), og 193 kvinner (41\%) hadde ikke tidligere født barn (nullipara). Omtrent halvparten av kvinnene (235/476, $49 \%$ ) hadde ikke tidligere fått utført provosert abort. Karakteristika for inkluderte kvinner er gjengitt i tabell 1. Median svangerskapsvarighet var 43 dager (variasjonsbredde 28-63). To til fire uker etter aborten møtte 415 kvinner til etterkontroll. 61 kvinner (13\%) møtte ikke til etterkontroll. 
Tabell 1

Karakteristika ved kvinnene som ble inkludert i prosjektet

\begin{tabular}{|lr|}
\hline Variabler & $\mathbf{n}=\mathbf{4 7 6}$ \\
\hline Svangerskapsvarighet i dager, median (variasjonsbredde) & $43(28-63)$ \\
\hline Alder, median (variasjonsbredde) & $30(17-47)$ \\
\hline Tidligere fødsler, $\mathrm{n}(\%)$ & \\
\hline 0 & $193(41)$ \\
\hline 1 & $83(17)$ \\
\hline 2 & $135(28)$ \\
\hline$\geq 3$ & $65(14)$ \\
\hline Tidligere aborter, $\mathrm{n}(\%)$ & \\
\hline 0 & $235(49)$ \\
\hline 1 & $179(38)$ \\
\hline$\geq 2$ & $62(13)$ \\
\hline
\end{tabular}

Graden av blødning ble registrert for 451 (95\%) av kvinnene under abortbehandlingen, og for $408(86 \%)$ ved etterkontrollen. Under abortbehandlingen oppga ni kvinner (2\%) svært mye blødning, 162 (36\%) mye blødning, 196 (44\%) moderat blødning, 69 (15\%) lett blødning og 15 (3\%) ingen blødning (tab 2). De første dagene etter abortbehandlingen oppga 26 kvinner (6\%) svært mye blødning, 160 (39\%) mye blødning, 178 (44\%) moderat blødning og 44 (11\%) lett blødning. Median varighet av blødning var 13 dager (variasjonsbredde 3-35).

\section{Tabell 2}

Grad av smerte og blødning registrert 4-6 timer etter inntak av misoprostol og grad av blødning de første dagene etter aborten. Dataene er innhentet ved bruk av spørreskjema under aborten og på etterkontrollen, 2-4 uker etter aborten

\begin{tabular}{|lrr|}
\hline \multicolumn{4}{|c|}{ 4-6 timer etter misoprostol, $\mathbf{n}(\%)$ De første dagene etter aborten, $\mathbf{n}(\%)$} \\
\hline Smerte & $\mathbf{n}=\mathbf{4 5 0}$ \\
\hline Ingen & $28(6)$ & \\
\hline Lett & $126(28)$ & \\
\hline Moderat & $191(42)$ & $\mathbf{n = 4 0 8}$ \\
\hline Sterk & $105(23)$ & $0(0)$ \\
\hline Blødning & $\mathbf{n = 4 5 1}$ & $44(11)$ \\
\hline Ingen & $15(3)$ & $178(44)$ \\
\hline Lett & $69(15)$ & $160(39)$ \\
\hline Moderat & $196(44)$ & $26(6)$ \\
\hline Mye & $162(36)$ & \\
\hline Svært mye & $9(2)$ &
\end{tabular}

Informasjon om smerter ble registrert for 450 av kvinnene under abortbehandlingen. Under abortbehandlingen hadde 28 kvinner (6\%) ingen smerter, 126 (28\%) lette smerter, 191 ( $42 \%)$ moderate smerter og 105 (23\%) sterke smerter (tab 2).

Graden av trygghet ved å være hjemme under aborten ble registrert for 426 kvinner under abortbehandlingen, og for 394 kvinner på etterkontrollen. Trygghetsopplevelsen ved å være hjemme under aborten er illustrert i figur 3. Under aborten rapporterte 379 kvinner (94\%) trygghetsskår på 8, 9 eller 10.368 kvinner (93\%) oppga trygghetsskår på 8, 9 eller 10 på etterkontrollen. Median trygghetsopplevelse rapportert under abortbehandlingen var 10 (variasjonsbredde 4-10). Også median trygghetsopplevelse vurdert på etterkontroll var 10 (variasjonsbredde 1-10). Under aborten rapporterte fem kvinner (1\%) trygghetsskår på 1, 2,3, eller 4. Fem kvinner (1\%) oppga trygghetsskår på 1, 2, 3, eller 4 på etterkontrollen. 


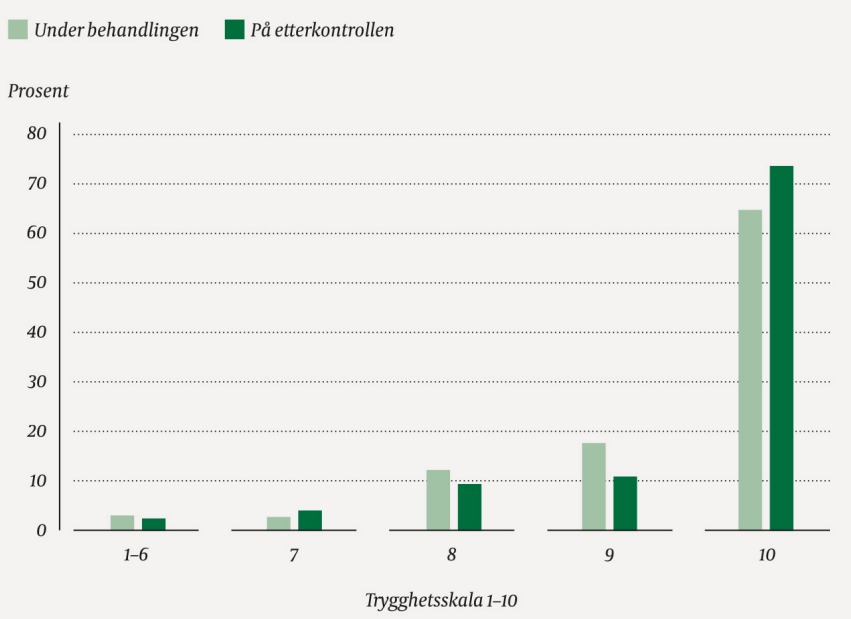

Figur $_{3}$ Opplevd grad av trygghet ved å vcere hjemme under aborten, registrert under abortbehandlingen og på etterkontrollen (1 = lavest, 10 = høyest trygghet)

Tilfredshet med behandlingen, herunder spørsmål om hvordan kvinnen opplevde abortbehandlingen, hvorvidt hun ville velge samme tilbud ved en eventuell senere abort, og om hun ville anbefale medikamentell abort hos avtalespesialist til andre i samme situasjon, er gjengitt i tabell 3. $42 \%$ (173/409) av kvinnene fant abortbehandlingen lettere enn forventet, og $96 \%$ (390/406) ville benyttet seg av medikamentell abort hos avtalespesialist ved en eventuell senere abort. $97 \%$ (392/405) av kvinnene ville anbefalt medikamentell abort hos avtalespesialist til andre i samme situasjon.

\section{Tabell 3}

Tilfredshet med abortbehandlingen. Dataene er innhentet ved bruk av spørreskjema på etterkontrollen, 2-4 uker etter aborten

\begin{tabular}{|lr|}
\hline Variabler & $\mathbf{n}(\%)$ \\
\hline Hvordan opplevde du aborten? & $\mathbf{n}=\mathbf{4 0 9}$ \\
\hline Lettere enn forventet & $173(42)$ \\
\hline Som forventet & $153(37)$ \\
\hline Tøffere enn forventet & $83(20)$ \\
\hline Hvis det var aktuelt å gjøre det på nytt, hva vil du velge? & $\mathbf{n = 4 0 6}$ \\
\hline Hjemmeabort i regi av avtalespesialist & $390(96)$ \\
\hline Hjemmeabort i regi av et sykehus & $0(0)$ \\
\hline Være på sykehus under aborten & $16(4)$ \\
\hline Vil du anbefale hjemmeabort hos avtalespesialist til andre? & $\mathbf{n = 4 0 5}$ \\
\hline Ja & $392(97)$ \\
\hline Nei & $13(3)$ \\
\hline
\end{tabular}

Informasjon om hvorvidt kvinnen hadde vært i kontakt med annet helsepersonell (inkludert sykehus) under abortbehandlingen ble registrert for 403 kvinner. 36 kvinner (9\%) hadde vært i kontakt med annet helsepersonell. Informasjon om kvinnen hadde ekstra konsultasjoner hos avtalespesialisten under abortbehandlingen ble registrert for 377 kvinner. 68 kvinner (18\%) hadde hatt en eller flere tilleggskonsultasjoner hos avtalespesialisten i forbindelse med aborten ( $\operatorname{tab} 4)$.

\section{Tabell 4}


Kontakt med annet helsepersonell, behov for ekstra konsultasjoner og tidsbruk hos avtalespesialist. Dataene er innhentet ved bruk av spørreskjema på etterkontrollen, 2-4 uker etter aborten

\begin{tabular}{|lr|}
\hline Variabler & $\mathbf{n}(\%)$ \\
\hline Kontakt med annet helsepersonell (inkludert sykehus)? & $\mathbf{n}=\mathbf{4 0 3}$ \\
\hline Ja & $36(9)$ \\
\hline Nei & $367(91)$ \\
\hline Ekstra konsultasjon hos avtalespesialisten? & $\mathbf{n}=377$ \\
\hline Ja & $68(18)$ \\
\hline Nei & $309(82)$ \\
\hline Tidsbruk per pasient ved første konsultasjon & $\mathbf{n}=427$ \\
\hline$<20$ minutter & $110(26)$ \\
\hline $20-40$ minutter & $266(62)$ \\
\hline$>40$ minutter & $51(12)$ \\
\hline Tidsbruk per pasient ved andre konsultasjon & $\mathbf{n = 3 8 4}$ \\
\hline$<20$ minutter & $200(52)$ \\
\hline $20-40$ minutter & $179(47)$ \\
\hline$>40$ minutter & $5(1)$ \\
\hline
\end{tabular}

$62 \%$ av førstegangskonsultasjonene (266/427) varte 20 til 40 minutter, $26 \%(110 / 427)$ mindre enn 20 minutter og $12 \%(51 / 427)$ over 40 minutter. Det ble avsatt mindre tid på etterkontrollene, $52 \%$ (200/384) varte mindre enn 20 minutter, $47 \%$ (179/384) mellom 20 og 40 minutter og $1 \%(5 / 384)$ mer enn 40 minutter (tab 4$)$.

\section{Diskusjon}

Studien av en pasientserie med 476 kvinner representerer de første erfaringene med å gi avtalespesialister adgang til å tilby medikamentelt utført abort før utgangen av 9 . svangerskapsuke. Det store flertallet av kvinnene var tilfredse med abortbehandlingen og ville anbefalt den til andre i samme situasjon. En liten andel av kvinnene var mindre tilfredse med behandlingen og ville ikke valgt medikamentell abort hos avtalespesialist ved en eventuell senere abort.

Resultatene viste at mange kvinner hadde moderate eller sterke smerter under aborten. Ved medikamentell abort er smerter en hyppig rapportert bivirkning og er å betrakte som en naturlig konsekvens av behandlingen (9-12). Ettersom metoden er forventet å være smertefull, er det av stor betydning å få tilstrekkelig smertestillende behandling. I prosjektet ble det gitt både skriftlig og muntlig informasjon om smerter. Alle kvinnene fikk også utdelt smertestillende medikamenter for bruk hjemme.

Vaginalblødning er også en nødvendig konsekvens av behandlingen (9-11). Fire til seks timer etter administrasjon av misoprostol oppga de fleste kvinnene (79\%) å ha moderat eller mye blødning. Ved etterkontrollen rapporterte $83 \%$ at de hadde moderat eller mye blødning de første dagene etter abortbehandlingen. Fire til seks timer etter administrasjon av misoprostol oppga få kvinner (2\%) å ha svært mye blødning, og heller ikke mange (6\%) hadde svært mye blødning dagene etter aborten. En median blødningstid på 13 dager er i samsvar med det som rapporteres i andre studier (9-11).

Under abortbehandlingen rapporterte de aller fleste kvinnene (94\%) en trygghetsskår mellom 8 og 10. Også på etterkontrollen rapporterte flertallet av kvinnene (93\%) høye trygghetsskår. God informasjon kan være med på å øke pasientens trygghet og mestringsevne i forhold til det som skal skje, og gi grunnlag for å foreta mer realistiske vurderinger (13). Ofte er det lettere å takle ubehag når dette er kjent på forhånd og samsvarer med forventningene. Vi mener at på grunn av god skriftlig og muntlig informasjon gitt på forhånd hadde kvinnene et realistisk forhold til smerter og blødning som en naturlig konsekvens av behandlingen, og derfor opplevde de høy grad av trygghet under aborten. 
Pasientenes tilfredshet etter medikamentell abort hos avtalespesialist var høy, ettersom de aller fleste ville valgt samme tilbud hvis de en annen gang skulle ha selvbestemt abort. De ville også anbefalt tilbudet hos avtalespesialist til andre i samme situasjon. Dette er i samsvar med resultatene fra andre studier, der man har vurdert pasienttilfredshet ved medikamentell abort som ble startet på sykehus og sluttført hjemme $(11,14,15)$. I prøveprosjektet hadde kvinnene selv valgt medikamentell abort hos avtalespesialist. Kvinner som søker abort er opptatt av selv å velge abortmetode $(10,16)$, og det er mulig at også det å kunne velge behandlingssted kan være av betydning for kvinnens opplevelse av trygghet og tilfredshet med behandlingstilbudet.

Få av kvinnene i prøveprosjektet ( $9 \%$ ) hadde kontakt med annet helsepersonell og/eller sykehus under abortbehandlingen, mens én av fem kvinner som mottok abortbehandling hadde behov for ekstra konsultasjon hos avtalespesialisten. Abortbehandling er en problemstilling som krever omfattende informasjon og grundig klinisk undersøkelse. Vi har ikke informasjon om ressursbruk (tidsbruk) i forhold til medikamentell abort utført på sykehus og kan derfor ikke sammenligne våre resultater med tilsvarende resultater fra sykehus.

\section{SVAKHETER VED STUDIEN}

Svakheter ved studien er at vi ikke har en sammenlignbar gruppe som har fått medikamentelt utført abort på sykehus. Om man hadde sammenlignet kvinnene som fikk behandling hos avtalespesialist, med «alle andre» kvinner som hadde fått medikamentelt utført abort på sykehus, ville man trolig få et godt resultat for kvinner som fikk medikamentelt utført abort hos avtalespesialist, uten at dette egentlig kunne tilskrives behandlingen hos avtalespesialisten. Grunnen er at pasientene som søkte behandling hos avtalespesialist, søkte seg dit og derfor kunne tenkes å favorisere behandling der.

En randomisert kontrollert studie ville være å foretrekke vitenskapelig sett, men ville kunne være vanskelig å gjennomføre og ha lav inklusjon. I en norsk studie så man på $\mathrm{i}$ hvilken grad kvinner var villige til å la seg randomisere for abortmetode (medisinsk eller kirurgisk abort) (10). Studien viste at 70 \% ikke ville la seg randomisere når det gjaldt metode.

\section{Konklusjon}

Prøveprosjektet har vist at et stort flertall av kvinnene som deltok i prosjektet, var fornøyde med å motta abortbehandling hos avtalespesialist og ville anbefalt det til andre. Få kvinner hadde kontakt med sykehus eller annet helsepersonell under abortbehandlingen.

\section{HOVEDBUDSKAP}

$94 \%$ av kvinnene som fikk utført abort hos avtalespesialist, opplevde behandlingen som svært trygg $42 \%$ av kvinnene opplevde aborten som lettere enn forventet

Nesten alle kvinnene i studien ville benytte seg av medikamentell abort hos avtalespesialist hvis de senere i livet skulle velge abort

\section{LITTERATUR:}

1. Sedgh G, Singh S, Shah IH et al. Induced abortion: incidence and trends worldwide from 1995 to 2008. Lancet 2012; 379: 625-32. [PubMed][CrossRef]

2. Folkehelseinstituttet. Medisinsk fødselsregister og abortregisteret - Statistikkbanker. https://www.fhi.no/hn/statistikk/statistikkalenderen/statistikkbanker/ (3.3.2018). 
3. Løkeland M, Bjørge T, Iversen OE et al. Implementing medical abortion with mifepristone and misoprostol in Norway 1998-2013. Int J Epidemiol 2017; 46: 643 - 51. [PubMed]

4. LOV-1975-o6-13-50. Lov om svangerskapsavbrudd (abortloven). https://lovdata.no/dokument/NL/lov/1975-06-13-50 (3-3.2018).

5. Bjørge L, Løkeland M, Oppegaard K. Provosert abort. Veileder i generell gynekologi. Oslo: Norsk gynekologisk forening, 2017.

https://legeforeningen.no/Fagmed/Norsk-gynekologisk-forening/Veileder-arkiv-utgatte-versjoner/vei leder-i-generell-gynekologi-2009/provosert-abort/(3.3.2018).

6. Worm Frandsen M, Rørbye C, Nilas L. Do women with a repeat termination of pregnancy prefer a medical or a surgical regimen? Acta Obstet Gynecol Scand 2014; 93:308 - 11. [PubMed][CrossRef]

7. World Health Organization. Safe abortion: technical and policy guidance for health systems. 2012. http://www.who.int/reproductivehealth/publications/unsafe_abortion/9789241548434/en/(3.3.2018).

8. Helse- og omsorgsdepartementet. Prop. 1 S (2010-2011) for budsjettåret 2011; 126. https://www.regjeringen.no/no/dokumenter/prop-1-s-20102011/id617556/(3.3.2018).

9. Bjørge L, Johnsen SL, Midbøe G et al. Early pregnancy termination with mifepristone and misoprostol in Norway. Acta Obstet Gynecol Scand 2001; 80: 1056 - 61. [PubMed][CrossRef]

10. Iversen OE, Midbøe G, Johnsen SL et al. Medikamentell abort - de første norske erfaringene. Tidsskr Nor Lægeforen 2003; 123: 2422 - 4. [PubMed]

11. Løkeland M, Iversen OE, Engeland A et al. Medical abortion with mifepristone and home administration of misoprostol up to 63 days' gestation. Acta Obstet Gynecol Scand 2014; 93: 647 - 53. [PubMed][CrossRef]

12. Teal SB, Dempsey-Fanning A, Westhoff C. Predictors of acceptability of medication abortion. Contraception 2007; 75: 224 - 9. [PubMed][CrossRef]

13. Grønnestad BK, Blystad A. Pasienters opplevelse av informasjon i forbindelse med en operasjon - en kvalitativ studie. Nordic Journal of Nursing Research 2004; 24: 4 - 8. [CrossRef]

14. Kopp Kallner H, Fiala C, Stephansson O et al. Home self-administration of vaginal misoprostol for medical abortion at 50-63 days compared with gestation of below 50 days. Hum Reprod 2010; 25: 1153- 7 . [PubMed][CrossRef]

15. Schaff EA, Fielding SL, Eisinger SH et al. Low-dose mifepristone followed by vaginal misoprostol at 48 hours for abortion up to 63 days. Contraception 2000; 61: 41 - 6. [PubMed][CrossRef]

16. Henshaw RC, Naji SA, Russell IT et al. Comparison of medical abortion with surgical vacuum aspiration: women's preferences and acceptability of treatment. BMJ 1993; 307: 714 - 7.

[PubMed][CrossRef]

Publisert: 28. mai 2018. Tidsskr Nor Legeforen. DOI: 10.4045/tidsskr.18.0041

(C) Tidsskrift for Den norske legeforening 2020. Lastet ned fra tidsskriftet.no 